\title{
The effects of immediate and delayed feedback on hand hygiene compliance
}

\author{
E Gavrieli' ${ }^{*}$, A Drach-Zahavy², I Tal', G Rahav', D Ben-David' \\ From 3rd International Conference on Prevention and Infection Control (ICPIC 2015) \\ Geneva, Switzerland. 16-19 June 2015
}

\section{Introduction}

Audit and feedback is widely used as a part of a multimodal strategy to improve hand hygiene $(\mathrm{HH})$ compliance. Few studies have investigated the effect of different feedback strategies.

\section{Objectives}

To compare delayed versus immediate feedback.

\section{Methods}

A prospective 5-step interventional study was conducted between 2012-2014 in 2 pediatric intensive care units (PICU and HPICU) at a tertiary medical center in Israel. The intervention steps included (1) baseline observations (2) training (3) providing delayed feedback in PICU versus both delayed and immediate feedback in HPICU (4) providing immediate feedback in PICU (5) final assessment stage. $\mathrm{HH}$ observations were conducted according to the 5-moment HH model. A Mixed Linear regression analysis was used to examine the models with repeated measurements. Each stage was defined relative to the baseline stage in 5 moments. In addition, each stage was defined in comparison to the previous stage

\section{Results}

A total of 8,159 observations were completed during the study period. HPICU HH compliance increased from $33.4 \%$ in the baseline stage to $71.8 \%$ at the final stage; PICU HH compliance increased from $30.92 \%$ to $67.1 \%$. When each stage was compared to the baseline, $\mathrm{HH}$ compliance rates of all WHO's 5-moment were significantly improved $(\mathrm{p}<.0001)$. Assessment the impact of each step showed that only immediate feedback was associated with a significant increase in $\mathrm{HH}$ compliance before clean/aseptic contact (HPICU 16.3\% (step 2)

${ }^{1}$ Infectious Diseases Depatment, Sheba Medical Center, Ramat Gan, Israel Full list of author information is available at the end of the article versus $45.0 \%$ (step 3); PICU $25.8 \%$ (step 3) versus $48.4 \%$ (step 4), $\mathrm{p}<0.001)$ ).

\section{Conclusion}

Implementation of a multifaceted intervention was associated with sustained improvement in $\mathrm{HH}$ adherence. Delayed feedback contributed to a slow but gradual increase at all stages, while immediate feedback contributed to a significant increase in $\mathrm{HH}$ compliance before clean/aseptic contact

\section{Disclosure of interest}

None declared.

\section{Authors' details}

${ }^{1}$ Infectious Diseases Depatment, Sheba Medical Center, Ramat Gan, Israel. ${ }^{2}$ Faculty of social welfare and health science, Haifa University, Haifa, Israel.

Published: 16 June 2015

doi:10.1186/2047-2994-4-S1-P287

Cite this article as: Gavrieli et al:: The effects of immediate and delayed feedback on hand hygiene compliance. Antimicrobial Resistance and Infection Control 2015 4(Suppl 1):P287.

Submit your next manuscript to BioMed Central and take full advantage of:

- Convenient online submission

- Thorough peer review

- No space constraints or color figure charges

- Immediate publication on acceptance

- Inclusion in PubMed, CAS, Scopus and Google Scholar

- Research which is freely available for redistribution 